This manuscript is the accepted version of the paper:

Interface shear properties of geosynthetics and construction and demolition waste from large-scale direct shear tests. Geosynthetics International, 23, No. 1, 62-70. DOI: 10.1680/jgein.15.00030

\title{
Interface shear properties of geosynthetics and construction and demolition waste from large-scale direct shear tests
}

\author{
Castorina Silva Vieira ${ }^{1}$ and Paulo M. Pereira ${ }^{2}$ \\ ${ }^{1}$ Assistant Professor, Faculty of Engineering, University of Porto, R. Dr. Roberto Frias, 4200-465 Porto, \\ Portugal, Telephone: +351 225081586, Telefax: +351 225081446, E-mail: cvieira@fe.up.pt (corresponding \\ author) \\ ${ }^{2}$ Research Fellow, Faculty of Engineering, University of Porto, R. Dr. Roberto Frias, 4200-465 Porto, \\ Portugal, Telephone: +351 225081613,Telefax: +351225081446 E-mail:pmpp@fe.up.pt
}

\begin{abstract}
In recent years environmental sustainability has demanded a progressive increase of waste recycling in general and waste value-added utilization in the construction industry in particular. As regards the application of Construction and Demolition Wastes (C\&DW) in geotechnical works, it has been noticed that the use of recycled aggregates is found mostly in road construction. Value-added utilization of C\&DW in geosynthetic reinforced structures is almost an unexplored field. This paper presents results of physical, mechanical and environmental characterization of recycled C\&DW, as well as the direct shear behaviour of three recycled C\&DW/geosynthetic interfaces. The C\&DW material was collected from a recycling plant and came from the demolition of single-family houses and the cleaning of land with illegal deposits of C\&DW. Two geogrids and one geocomposite reinforcement (high strength geotextile) were used to assess the behaviour of C\&DW/geosynthetic interfaces. The environmental characterization of the C\&DW, carried out through leaching tests, did not show environmental concerns. Direct shear test results have demonstrated that properly selected and compacted C\&DW can exhibit shear strength similar to natural soils. The coefficients of interaction achieved for C\&DW/geosynthetic interfaces compare well with those reported in the literature for soil/geosynthetic interfaces under similar conditions, which supports the feasibility of using these recycled materials as backfill in geosynthetic reinforced structures.
\end{abstract}


KEYWORDS: Geosynthetics; Environmental sustainability; Construction and Demolition Wastes; Interface shear strength; Large scale direct shear tests

\section{Introduction}

The reduction of non-renewable natural resource use is a constant concern in environmental preservation and encourages the use of alternative materials. About $50 \%$ of the materials extracted from the earth's crust are used in construction industry (European Commission, 2001). The significant consumption of minerals and ores, about 15ton/year per capita in the European Union (European Commission, 2007), makes it imperative to promote major changes in consumption patterns. The recycling of construction materials is an ancient practice, carried out by the Egyptians, Greeks and Romans. In the modern era it began to find expression in Europe after the Second World War with the use of crushed aggregates in the reconstruction of buildings.

Over recent years environmental sustainability has demanded a progressive increase of waste recycling in the construction industry. Several studies and applications of recycled Construction and Demolition Wastes (C\&DW) have been performed, mainly related to the production of aggregates for use in concrete (Behera et al. 2014; Medina et al. 2014; Rao et al. 2007; Silva et al. 2014) and for use in base layers of transportation infrastructures (Agrela et al. 2012; Herrador et al. 2011; Jiménez et al. 2012; Poon and Chan, 2006). As regards the application of C\&DW in geotechnical works, it has been noticed that waste reutilization is performed mainly in road construction, particularly in the base and sub-base layers of the infrastructures. Outside the scope of road infrastructures, there are not many references to C\&DW applications in embankments. Apart from some recent studies (Arulrajah et al. 2014; Santos et al. 2013, 2014), the value-added utilization of recycled C\&DW in geosynthetic reinforced structures is almost an unexplored field.

To broaden the potential application of C\&DW in geotechnical works and, simultaneously, to assess the replacement of natural soils traditionally used in geosynthetic reinforced structures with recycled C\&DW, a research project was carried out. The characterization of recycled $\mathrm{C} \& \mathrm{DW} / \mathrm{geosynthetic} \mathrm{interfaces} \mathrm{behaviour} \mathrm{was} \mathrm{one} \mathrm{of} \mathrm{the} \mathrm{main} \mathrm{goals} \mathrm{of} \mathrm{the} \mathrm{project.}$

The interaction mechanism between the reinforcement and the fill material has the utmost importance in the design of geosynthetic reinforced structures. This mechanism depends on the fill properties, reinforcement characteristics and elements (fill and reinforcement) interaction. 
Accurate identification of the interaction mechanism and the choice of the most suitable test for its characterization are important factors. The reinforcements tend to be pulled out in the upper part of the retained reinforced soil mass, so the soil-reinforcement interaction should be characterised by laboratory pullout tests. On the other hand, soil sliding is expected near the base of the slope and the interaction between the fill and the geosynthetic material is better characterised through direct shear tests (Vieira et al. 2013).

In recent decades many researchers have investigated the shear properties of soilgeosynthetic interfaces through direct shear tests (Liu and Martinez 2014; Esmaili et al. 2014; Khoury et al. 2011; Lee and Manjunath 2000; Liu et al. 2009a; Nakamura et al. 1999; Vieira et al. 2013). More recently, Santos and Vilar (2008) carried out direct shear and pullout tests to characterize the behaviour of C\&DW/geogrid interfaces. To assess the viability of using geogrid-reinforced construction and demolition materials as alternative construction materials, Arulrajah et al. (2014) conducted direct shear tests using biaxial and triaxial geogrids as reinforcement elements.

This paper presents the results of direct shear tests carried out on a large scale apparatus to characterize the shear strength of recycled C\&DW, with grain size distribution similar to the natural soils traditionally used in Portugal as backfill material of geosynthetic reinforced structures, as well as to assess the interaction mechanism between recycled C\&DW and three distinct geosynthetics (a uniaxial HDPE geogrid, a uniaxial PET geogrid and a high strength geotextile). Physical and environmental characterization of the recycled C\&DW are also presented.

\section{Materials and methods}

A fine grain recycled C\&DW, coming mainly from the demolition of single-family houses and the cleaning of land with illegal deposits of C\&DW (Figure 1) was used in this study.

The constituents of the C\&DW can be found in Appendix A. The predominant materials of this recycled C\&DW are concrete, mortar and unbound aggregates. A significant amount of soil was also identified.

The gradation of the material was determined according to the standard ISO/TS 17892-4 (2004). The particle size distribution determined by sieving and sedimentation is represented in Figure 2. The grading ranges recommended by the Federal Highway Administration (FHWA 2010) for Reinforced Soil Slopes (RSS) and Mechanically Stabilized Earth Walls (MSEW) and by the National Concrete Masonry Association - NCMA (NCMA 2010) for Segmental 
Retaining Walls (SRW) are also shown in Figure 2. The recycled C\&DW under analysis satisfies the guidelines for RSS structures and SRW structures according to FHWA and NCMA respectively, excepting a slight deviation between $0.5 \mathrm{~mm}$ and $3 \mathrm{~mm}$.

Additional properties of the recycled C\&DW and the standardised procedures used to estimate them are provided in Appendix A.

Three commercially available geosynthetics were used in this study: an extruded uniaxial high density polyethylene (HDPE) geogrid, a laid uniaxial geogrid made of extruded polyester (PET) bars with welded rigid junctions, and a high-strength composite geotextile consisting of polypropylene continuous-filament needle-punched nonwoven and high-strength polyester yarns (unidirectional reinforcement). Table 1 summarizes the main properties of the geosynthetics.

The direct shear tests were performed on a large scale direct shear device. The shear box comprises an upper container, fixed horizontally, with dimensions of $300 \mathrm{~mm} \times 600 \mathrm{~mm}$ in width and length and $150 \mathrm{~mm}$ high, and a lower container $340 \mathrm{~mm} \times 800 \mathrm{~mm}$ in width and length and $100 \mathrm{~mm}$ high, rigidly fixed to a mobile platform running on low friction linear guides. A rigid base or a rigid ring (reduction box) can be inserted into the lower container. More details about this prototype can be found in Vieira et al. (2013).

Reduced contact area direct shear tests were carried out to characterize the shear strength of recycled $\mathrm{C} \& \mathrm{DW}$ and $\mathrm{C} \& \mathrm{DW} /$ geogrid interfaces. Following the recommendations of EN ISO 12957-1 (2005), direct shear tests with the rigid base placed inside the lower box (constant

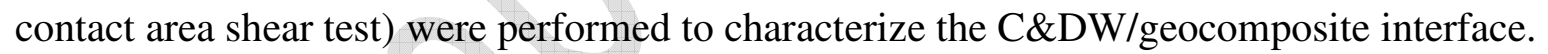

The C\&DW was put into the shear boxes, at its air-dried water content, with relative density ( $\left.\mathrm{I}_{\mathrm{D}}\right)$ of $70 \%$. For reduced contact area direct shear tests, each container was filled with four layers of thickness equal to $25 \mathrm{~mm}$ to the target unit weight. Geogrid specimens were held with screws at the front edge of the lower box outside the shear area.

To prevent relative displacement between the geosynthetic and the rigid support, an aluminium oxide abrasive sheet (P80 type) was glued to the support and the geocomposite specimen was held with screws at the two edges of the lower box. The C\&DW was placed inside the upper shear box and compacted under similar conditions as those described for reduced contact area direct shear tests.

All direct shear tests were carried out with a constant displacement rate of $1 \mathrm{~mm} / \mathrm{min}$ at normal stresses of 50,100 and $150 \mathrm{kPa}$. To evaluate the shear strength of the recycled C\&DW, 
131 direct shear tests at normal stress of $25 \mathrm{kPa}$ were also carried out. For assessing the variability

132 of the results, each test was performed three times under similar conditions.

133 Prior to shearing, the normal stress was applied to the specimens for one hour. After this

134 period of time, the settlement of the C\&DW under the pre-established normal stress was

135 stabilised in all specimens. Vertical displacements of the loading plate before and during shear

136 were recorded with a linear variable displacement transducer (LVDT). The tests were stopped

137 once the horizontal shear displacement reached approximately $60 \mathrm{~mm}$.

\section{RESULTS AND DISCUSSION}

\section{3.1. Mechanical and environmental characterization of the recycled $C \& D W$}

141 Regardless of the fact that the use of C\&DW in geosynthetic reinforced structures can attain

142 a good mechanical performance, environmental concerns regarding the potential contamination

143 of groundwater impose an assessment of the release of dangerous substances through the

144 leaching behaviour of these recycled materials. Thus, laboratory leaching tests were carried out 145 in accordance with European Standard EN 12457-4 (2002).

146 Table 2 presents the leaching test results, as well as the acceptance criteria of maximum 147 leached concentration for inert landfill, as defined by the European Council Decision 148 2003/33/EC.

149 It can be concluded from the analysis of the results presented in Table 2 that only sulphate 150 exceeded the maximum limit established by European and Portuguese legislation. However, 151 Directive 2003/33/EC states that "if the waste does not meet these values for sulphate, it may 152 still be considered as complying with the acceptance criteria if the leaching does not exceed $1536000 \mathrm{mg} / \mathrm{kg}$ at $\mathrm{L} / \mathrm{S}=10 \mathrm{l} / \mathrm{kg}$, determined either by a batch leaching test or by a percolation test 154 under conditions approaching local equilibrium."

155 The shear strength of the recycled C\&DW was evaluated through direct shear tests carried 156 out under confining pressures of 25, 50, 100 and $150 \mathrm{kPa}$. Shear stress-shear displacement 157 curves of direct shear tests conducted under normal stress of $50 \mathrm{kPa}$ are illustrated in Figure 3.

158 Results of direct shear tests carried out under similar conditions $\left(I_{D}=70 \%\right.$ and $\left.\sigma=50 \mathrm{kPa}\right)$ with 159 a fine grain sand $\left(D_{50}=0.45 \mathrm{~mm} ; C_{u}=1.9\right)$ and a coarse grain sand $\left(D_{50}=1.32 \mathrm{~mm} ; C_{u}=3.6\right)$ 160 are also represented in Figure 3.

161 Figure 3 shows low variability in the results, as the maximum difference among the values 162 reached in three tests for peak shear strength and large displacement shear strength is lower 163 than $12 \%$ and $4 \%$, respectively. Under similar conditions, the recycled C\&DW had higher shear 
164 strength than that of natural soils, although the peak shear strength tends to be reached with 165 larger shear displacements.

166 The evolution of shear stress as a function of shear displacement for direct shear tests carried out under discrete confining pressures $(25,50,100$ and $150 \mathrm{kPa})$ is illustrated in Figure 4. In general, the shear stress-shear displacement curves show a well-defined peak shear strength for shear displacements that increased with normal stress. With the exception of direct shear tests carried out under normal stress of $25 \mathrm{kPa}$, for which the maximum difference among the values of peak shear strength reached in the three tests is approximately $30 \%$, the variability of the results is not significant.

The difficulties associated with direct shear tests under lower confining pressures are well known. Therefore, the highest variability recorded in the direct shear tests at $25 \mathrm{kPa}$ is not surprising.

176 Several experimental studies have suggested that the failure criteria of many soils are not 177 linear, particularly in the range of small normal stresses (Bishop et al. 1965; Maksimovic 1989; 178 Baker 2004). The cohesion of a soil, defined as the shear strength when the normal stress is 179 null, can be true or apparent. True cohesion appears in cemented soils and in overconsolidated soils. Apparent cohesion can result from soil matric suction in unsaturated soils, as well as from the intercept in the shear stress axis when a linear failure envelope is adjusted to a curved failure envelope.

Among the nonlinear shear strength envelopes, the most commonly used relation between the normal stress, $\sigma$, and the shear stress, $\tau$, has the general form $\tau=A \sigma^{\mathrm{b}}$, where A and $\mathrm{b}$ are constants with no physical meaning and depending on the units (Eid 2010).

Two failure envelopes were fitted to the peak shear strengths recorded in the tests carried out to characterise the recycled C\&DW (Figure 5): the best fit straight line (Mohr-Coulomb failure criterion) and the power-law relation that best represents the results.

Figure 5 shows that both failure envelopes fit the results with similar correlation coefficients,

$190 \mathrm{R}^{2}$. For normal stresses higher than $40 \mathrm{kPa}$ the shear strength failure envelopes are very close. 191 As expected, the main difference occurs for low normal stresses.

192 Due to the composition of this C\&D material, some cohesion is expected. The nonlinear 193 failure envelope plotted in Figure 5 also suggests this. Even so, the estimated cohesion value 194 based on Mohr-Coulomb failure criterion may have an apparent component resulting from the 195 adjustment of a linear failure envelope for low normal stress. 
The failure envelopes presented in Figure 5 point out the importance of limiting the range of validity of the estimated shear strength parameters based on linear failure envelopes. Following the Coulomb failure criterion, the cohesion and the friction angle of the recycled C\&DW is $20.9 \mathrm{kPa}$ and $43.1^{\circ}$, respectively.

Figure 6 compares peak and large displacement shear strength, as well as the corresponding linear best fit straight lines. The large displacement shear strengths were estimated as the mean values of the shear stresses recorded for displacements greater than 50mm (Figure 4). Following the Coulomb failure criterion, the large displacement shear strength can be defined by a friction angle of $40.9^{\circ}$ and cohesion of $4.0 \mathrm{kPa}$. Comparing these parameters with those for peak shear strength (peak friction angle $=43.1^{\circ}$ and cohesion $=20.9 \mathrm{kPa}$ ), a slight decrease in the friction angle but a large reduction (higher than $80 \%$ ) of the cohesive term is noticed.

Even if most of the guidelines from different countries explicitly indicate the use of peak friction angles in the design (FHWA 2010; BS 8006 2010; NCMA 2010; EBGEO 2011), the use of peak shear strength parameters instead of residual shear strength parameters in the design of geosynthetic reinforced soil structures is not consensual. Jewell (1996) suggests the selection of a design value for the soil shearing resistance equal to the critical state shear resistance, and Leshchinsky (2001) proposes a hybrid approach where the critical slip surface is determined based on peak shear strength and the required long-term reinforcement strength is estimated using the residual shear strength parameters.

Regarding the cohesion of the fill material, earlier versions of some guidelines have precluded the cohesive component of the shear strength, but recent editions (AASHTO 2012; BS 8006: 2010) allow the use of cohesive fills. Moreover, based on the evidence that there are many reinforced soil walls that have been built with granular backfills having significant fines content and that in general these walls have performed very well, Miyata and Bathrust (2007) extended the K-Stiffness method, developed to estimate the maximum reinforcement loads in reinforcement layers of reinforced soil walls, to cohesive backfill materials.

The shear strength achieved for this recycled C\&DW is encouraging, since it compares with the values for natural soils. Nevertheless, the cohesion should be used with great caution in design, due to its significant reduction for large strain conditions.

\subsection{Characterization of Recycled C\&DW/geosynthetic interfaces}

The evolution of the shear stresses with the imposed shear displacement recorded in direct shear tests carried out to characterize C\&DW/geosynthetic interfaces under distinct values of 
confining pressure is illustrated in Figure 7. Figure 7(a) refers to the interface between the

230 recycled C\&DW and the HDPE geogrid (GGR1), Figure 7(b) presents the results related to the 231 PET geogrid (GGR2) and Figure 7(c) shows the curves for the interface between the recycled 232 C\&DW and the high-strength composite geotextile (GCR).

233 In general and as observed for the recycled C\&DW, the shear stress-shear displacement 234 curves show a well-defined peak shear strength recorded for shear displacements that increased 235 with the confining pressure, followed by a reduction of shear stress and an almost constant shear 236 stress stage (residual shear strength). The results presented in Figure 7 provide evidence of 237 reduced variability of the results.

$238 \quad$ Figure 8 presents peak and large displacement shear strengths achieved in direct shear tests carried out to characterize the interfaces under analysis and the corresponding linear best fit straight lines. Shear strength parameters of the interfaces are summarized in Table 3.

241 Similar to what was observed in the characterization of recycled C\&DW, the recycled $242 \mathrm{C} \& D W / g e o g r i d$ interfaces underwent a slight decrease in the friction angle and a significant 243 reduction of the cohesive component for large shear displacements. For the C\&DW/geotextile 244 (GCR) interface the decrease in the friction angle for large shear displacements was more pronounced than that recorded for C\&DW/geogrid interfaces. This probably results from the mobilisation of the internal C\&DW strength along the geogrid apertures, which does not exist in the high strength geotextile (GCR).

The interface between the recycled C\&DW and the PET geogrid (GGR2) showed higher shear strength parameters, with a particularly high peak adhesion. This evidence could be explained by the large openings of the PET geogrid which allows a significant area where the

\subsection{Coefficients of interaction}

The coefficient of interaction between the backfill and the reinforcement is one of the key parameters in the design of geosynthetic reinforced structures. When the interaction between both materials is characterized through direct shear tests, the coefficient of interaction, $\mathrm{f}_{\mathrm{g}}$, can be defined as the ratio of the maximum shear stress in a C\&DW/geosynthetic direct shear test,

$$
\mathrm{f}_{\mathrm{g}}=\frac{\tau_{\mathrm{C \& DW} / \mathrm{geo}}^{\max }(\sigma)}{\tau_{\mathrm{C} \text { DW }}^{\max }(\sigma)}
$$


As each direct shear test was carried out three times under similar conditions, the coefficient of interaction should be estimated by the ratio of the mean value of maximum shear stresses recorded in the C\&DW/geosynthetic direct shear tests, to the mean value of maximum shear stresses reached in shear tests on C\&DW, under the same normal stress $\sigma$ :

$$
\mathrm{f}_{\mathrm{g}}^{\mathrm{m}}=\frac{\text { average }\left\{\tau_{\mathrm{C \& DW} / \mathrm{geo}}^{\mathrm{max}, 1}(\sigma) ; \tau_{\mathrm{C} \& \mathrm{DW} / \text { geo }}^{\max , 2}(\sigma) ; \tau_{\mathrm{C \& DW} / \text { geo }}^{\max , 3}(\sigma)\right\}}{\text { average }\left\{\tau_{\mathrm{C} \& \mathrm{DW}}^{\mathrm{max}, 1}(\sigma) ; \tau_{\mathrm{C} \& \mathrm{DW}}^{\mathrm{max}, 2}(\sigma) ; \tau_{\mathrm{C} \& \mathrm{DW}}^{\mathrm{max}, 3}(\sigma)\right\}}
$$

Figure 9 presents the coefficients of interaction, as a function of the normal stress, for the interfaces under analysis. For C\&DW/geogrid interfaces the coefficients of interaction increased with the confining pressure, the highest values being recorded for the interface with PET geogrid (GGR2). An increase trend of the coefficient of interaction is also noted for C\&DW/geotextile (GCR) interface. Notwithstanding, the values for normal stress of $50 \mathrm{kPa}$ and $100 \mathrm{kPa}$ are quite similar.

The coefficients of interaction are in the ranges $0.64-0.74,0.76-0.83$ and $0.67-0.74$ for the interfaces C\&DW/GGR1, C\&DW/GGR2 and C\&DW/GCR, respectively.

The coefficients of interaction achieved for the C\&DW/GGR2 (PET geogrid) interface are similar to the values reported by Abu-Farsakh et al. (2007) for clay/geogrid interfaces (see Appendix B). The values of $\mathrm{f}_{\mathrm{g}}$ achieved in the present study for $\mathrm{C} \& \mathrm{DW} / \mathrm{geog}$ rid interfaces are lower than those reported by Liu et al. (2009b) for sand/PET geogrid interfaces and by Ferreira et al. (2013) for residual soil/biaxial geogrid interface. However, they are higher than those presented by Arulrajah et al. (2014) for interfaces between a polypropylene biaxial geogrid and recycled concrete aggregate or crushed bricks.

For the interface between the C\&DW and the high strength geotextile (GCR) the coefficients of interaction are lower than those reported by Vieira et al. (2013) for an interface between a similar high strength geotextile and a poorly graded sand. Nevertheless, they are within the same order of magnitude as those presented by Ferreira et al. (2013) for an interface between a residual soil from granite and a geotextile, and those reported by Liu et al. (2009b) for sand/geotextile interfaces.

Taking into account the significant reduction of the cohesive component of shear strength for large shear conditions either for the C\&DW or for C\&DW/geosynthetic interfaces, coefficients of interaction for residual shear strength were also estimated. Their values were determined by equation (2) replacing the maximum shear strengths by residual shear strengths.

The coefficients of interaction for residual shear strengths are in the ranges 0.64-0.77, 0.83- 
respectively. Except for the interface C\&DW/GGR2, for which the coefficients of interaction for residual shear strength were higher than those for peak shear strength, the coefficients of interaction for residual shear strengths are in similar ranges to those presented for peak shear strength.

\section{Conclusions}

The interaction mechanism between recycled C\&DW, with grain size distribution similar to the natural soils traditionally used as backfill material of geosynthetic reinforced structures in Portugal, and three geosynthetics (a uniaxial HDPE geogrid, a uniaxial PET geogrid and a high strength geotextile) was studied through large scale direct shear tests. Physical, mechanical and environmental characterization of the recycled C\&DW was also reported.

The environmental characterization of the C\&DW, carried out through leaching tests, has shown that this C\&DW meets the acceptance criteria for inert landfill. No environmental concerns were identified.

Based on the analysis and interpretation of direct shear tests results, the following conclusions can be drawn:

- properly selected and compacted C\&DW can exhibit shear strength similar to (or even higher) the backfill materials commonly used in the construction of geosynthetic reinforced structures;

- comparing peak and residual shear strength parameters, a slight decrease in the friction angle but a large reduction of the cohesive term for large shear displacement conditions was noticed. This finding is valid either for C\&DW shear strength or for C\&DW/geosynthetic interface shear strength;

- the cohesion estimated based on Mohr-Coulomb failure criterion may have an apparent component resulting from the adjustment of a linear shear strength failure envelope for low normal stresses. The validity of the shear strength parameters is limited to the range of tested normal stresses;

- in general the coefficients of interaction achieved for C\&DW/geosynthetic interfaces compare well with those reported in the literature for soil/geosynthetic interfaces under similar conditions.

The shear strength achieved for this recycled C\&DW is encouraging, since it compares with the values for natural soils. Nevertheless, the cohesion should be used with great caution in design, due to the significant reduction for large strain conditions. 


\section{ACKNOWLEDGMENTS}

The authors would like to thank the Portuguese Science and Technology Foundation (FCT) and FEDER for financial support through the Research Project: FCOMP-01-0124-FEDER028842, RCD-VALOR - Sustainable application of Recycled Construction and Demolition Wastes (C\&DW) in geosynthetics reinforced structures (PTDC/ECM-GEO/0622/2012). The authors also thank Tensar International, Naue and TenCate Geosynthetics Iberia for providing the geosynthetics used in this study.

\section{REFERENCES}

AASHTO (2012). LRFD Bridge Design Specifications. 3rd Edition, Washington DC.

Abu-Farsakh, M., Coronel, J. \& Tao, M. (2007). Effect of soil moisture content and dry density on cohesive soil-geosynthetic interactions using large direct shear tests. Journal of Materials in Civil Engineering, 19, No. 7, 540-9.

Agrela, F., Barbudo, A., Ramírez, A., Ayuso, J., Carvajal, M.D. \& Jiménez, J.R (2012). Construction of road sections using mixed recycled aggregates treated with cement in Malaga, Spain. Resources, Conservation and Recycling, 58, 98-106.

Arulrajah, A., Rahman, M.A., Piratheepan, J., Bo, M.W. \& Imteaz, M.A. (2014). Evaluation of Interface Shear Strength Properties of Geogrid-Reinforced Construction and Demolition Materials using a Modified Large Scale Direct Shear Testing Apparatus. Journal of Materials in Civil Engineering, 26, No. 5, 974-82.

Baker, R. (2004). Nonlinear Mohr Envelopes Based on Triaxial Data. Journal of Geotechnical and Geoenvironmental Engineering, 130, No. 5, 498-506.

Behera, M., Bhattacharyya, S.K., Minocha, A.K., Deoliya, R. \& Maiti, S. (2014). Recycled aggregate from $C \& D$ waste $\&$ its use in concrete - A breakthrough towards sustainability in construction sector: A review. Construction and Building Materials, 68, 501-16.

Bishop, A.W., Webb, D.L. \& Lewin, P.I. (1965). Undisturbed samples of London Clay from the Ashford Common shaft: Strength-effective normal stress relationship. Geotechnique, 15, No. 1, 1-31.

BS 8006 (2010). Code of practice for strengthened/reinforced soils and other fills. British Standard Institution. 
Council Decision 2003/33/EC (2003). Council Decision establishing criteria and procedures for the acceptance of waste at landfills pursuant to Article 16 of and Annex II to Directive 1999/31/EC. Official Journal of European Union L11/27.

EBGEO (2011). Recommendations for design and analysis of earth structures using geosynthetic reinforcements - EBGEO, German Geotechnical Society: Ernst \& Sohn GmbH \& Co. KG.

Eid, H. T. (2010). Two- and three-dimensional analyses of translational slides in soils with nonlinear failure envelopes. Canadian Geotechnical Journal, 47, No. 4, 388-399.

EN 12457-4 (2002). Characterisation of waste - Leaching - Compliance test for leaching of granular waste materials and sludges - Part 4: One stage batch test at liquid to solid ratio of $101 / \mathrm{kg}$ for materials with particle size below $10 \mathrm{~mm}$ (without or with size reduction). CEN.

EN ISO 12957-1 (2005). Geosynthetics - Determination of the friction characteristics - Part 1: Direct shear test. CEN - TC 189.

Esmaili, D., Hatami, K. \& Miller, G.A.(2014). Influence of matric suction on geotextile reinforcement-marginal soil interface strength. Geotextiles and Geomembranes, 42, 13953.

European Commission (2001). Competitiveness of the Construction Industry, A report drawn up by the Working Group for Sustainable Construction with participants from the European Commission, Member States and Industry, 2001. http://www.etnpresco.net/library/SustConst_EC-TaskGroup.pdf (September 2014).

European Commission (2007). Analysis of the competitiveness of the non-energy extractive industry in the EU, Commission of the European Communities, SEC(2007) 771 http://ec.europa.eu/enterprise/sectors/metals-minerals/files/sec_2007_771_en.pdf (September 2014).

Ferreira, F.B., Vieira, C.S. \& Lopes, M.L. (2013). Analysis of soil-geosynthetic interfaces shear strength through direct shear tests. Proc. of the International Symposium on Design and Practice of Geosynthetic-Reinforced Soil Structures. Bologna, Italy, 14-16 October, pp. 44-53.

FHWA (2010). Design and construction of mechanically stabilized earth walls and reinforced soil slopes. FHWA-NHI-10-024, FHWA-NHI-10-025, Berg, R.R.; Christopher, B.R. and Samtani, N.C., Washington D.C. 
Herrador, R., Pérez, P., Garach, L, \& Ordóñez, J. (2011). Use of recycled Construction and Demolition Waste aggregate for road course surfacing. Journal of Transportation Engineering, 138, 182-90.

ISO/TS 17892-4 (2004). Geotechnical investigation and testing - Laboratory testing of soil Part 4: Determination of particle size distribution (CEN).

Jewell, R.A. (1996). Soil reinforcement with geotextiles. London: Special Publication 123 CIRIA, Thomas Telford.

Jiménez, J.R., Ayuso. J., Agrela, F., López, M. \& Galvín, A.P. (2012). Utilisation of unbound recycled aggregates from selected $\mathrm{CDW}$ in unpaved rural roads. Resources, Conservation and Recycling, 58, 88-97.

Khoury, C. N., G. A. Miller and K. Hatami (2011). Unsaturated soil-geotextile interface behavior. Geotextiles and Geomembranes, 29, No. 1, 17-28.

Lee, K.M. \& Manjunath, V.R. (2000). Soil-geotextile interface friction by direct shear tests. Canadian Geotechnical Journal, 37, 238-52.

Leshchinsky, D. (2001). Design dilemma: use peak or residual strength of soil. Geotextiles and Geomembranes, 19, 111-25.

Liu, C.-N., Ho, Y.-H. \& Huang, J.-W. (2009a). Large scale direct shear tests of soil/PET-yarn geogrid interfaces. Geotextiles and Geomembranes, 27, 19-30.

Liu, C.-N., Zornberg, J.G., Chen, T.-C., Ho, Y.-H. \& Lin, B.-H. (2009b). Behavior of geogridsand interface in direct shear mode. Journal of Geotechnical and Geoenvironmental Engineering, 135, No. 12, 1863-1871.

Liu, H. and J. Martinez (2014). Creep behavior of sand-geomembrane interfaces. Geosynthetics International, 21, No. 1, 83-88.

Maksimovic, M. (1989). Nonlinear failure envelope for soils. Journal of Geotechnical Engineering, 115, No. 4, 581-586.

Medina, C., Zhu, W., Howind, T., Rojas, M.I.S. \& Frías, M. (2014). Influence of mixed recycled aggregate on the physical - mechanical properties of recycled concrete. Journal of Cleaner Production, 68, 216-225.

Miyata, Y. \& Bathrust, R.J. (2007). Development of the K-stiffness method for geosynthetic reinforced soil walls constructed with c - f soils. Canadian Geotechnical Journal, 44, 1391-1414. 
Nakamura, T., Mitachi, T. \& Ikeura, I. (1999). Direct shear testing method as a means for estimating geogrid-sand Interface shear - displacement behavior. Soils and Foundations, 39, No.4, 1-8.

NCMA (2010). Design Manual for Segmental Retaining Walls. 3rd Edition, National Concrete Masonry Association.

Poon, C.S. \& Chan, D. (2006). Feasible use of recycled concrete aggregates and crushed clay brick as unbound road sub-base. Construction and Building Materials, 20, 578-585.

Rao, A., Jha, K.N. \& Misra, S. (2007). Use of aggregates from recycled construction and demolition waste in concrete. Resources, Conservation and Recycling, 50, 71-81.

Santos, E.C.G., Palmeira, E.M. \& Bathurst, R.J. (2013). Behaviour of a geogrid reinforced wall built with recycled construction and demolition waste backfill on a collapsible foundation. Geotextiles and Geomembranes, 39, 9-19.

Santos, E.C.G., Palmeira, E.M. \& Bathurst, R.J. (2014). Performance of two geosynthetic reinforced walls with recycled construction waste backfill and constructed on collapsible ground. Geosynthetics International, 21, No. 4, 256-69.

Santos, E.C.G. \& Vilar, O.M. (2008). Use of recycled Construction and Demolition Wastes (RCDW) as backfill of reinforced soil structures. Proc. of the 4th European Geosynthetics Conference - EUROGEO 4. Edinburgh, 7-10 September.

Silva, R.V., Brito, J. \& Dhir, R.K. (2014). Properties and composition of recycled aggregates from construction and demolition waste suitable for concrete production. Construction and Building Materials, 65, 201-217.

Vieira, C.S., Lopes, M.L. \& Caldeira, L.M. (2013). Sand-geotextile interface characterisation through monotonic and cyclic direct shear tests. Geosynthetics International, 20, No. 1, 26-38.

\section{NOTATIONS}

Basic SI units are given in parentheses.

$$
\text { c - soil cohesion }(\mathrm{Pa})
$$

$\mathrm{c}_{\mathrm{a}}$ - adhesion $(\mathrm{Pa})$ 
$\mathrm{c}_{\mathrm{a}, \mathrm{cv}}$ - adhesion corresponding to large displacement shear strength $(\mathrm{Pa})$

$453 \quad \mathrm{c}_{\mathrm{a}, \mathrm{p}}$ - adhesion corresponding to the peak shear strength $(\mathrm{Pa})$

$454 \quad \mathrm{C}_{\mathrm{u}}$ - soil uniformity coefficient (dimensionless)

$455 \quad \mathrm{D}_{\mathrm{i}}$ - diameter corresponding to $\mathrm{i} \%$ passing $(\mathrm{m})$

$456 \quad \mathrm{f}_{\mathrm{g}}$ - coefficient of interaction (dimensionless)

$457 \quad \mathrm{f}_{\mathrm{g}}^{\mathrm{m}}$ - coefficient of interaction estimated as a mean value (dimensionless)

$458 \quad \mathrm{f}_{\mathrm{g}}^{\mathrm{p}}$ - coefficient of interaction estimated by shear strength parameters (dimensionless)

$459 \quad \mathrm{I}_{\mathrm{D}}$ - relative density or density index (dimensionless)

$460 \quad \mathrm{~W}_{\mathrm{opt}}$ - soil optimum moisture content (dimensionless)

$461 \delta$ - interface friction angle $\left({ }^{\circ}\right)$

$462 \delta_{\mathrm{cv}}$ - interface friction angle for large relative displacements (degrees)

$463 \delta_{\mathrm{p}}$ - interface peak friction angle (degrees)

$464 \phi$ - soil internal friction angle (degrees)

$465 \quad \gamma_{d \max }$ - soil maximum dry unit weight $\left(\mathrm{N} / \mathrm{m}^{3}\right)$

$466 \quad \sigma-$ normal stress $(\mathrm{Pa})$

$\tau$ - shear stress $(\mathrm{Pa})$

$\tau_{\mathrm{C} \& \mathrm{DW}}^{\max }(\sigma)$ - maximum shear stress in direct shear test on C\&DW under normal stress $\sigma(\mathrm{Pa})$ 
483

484

485

486

487

488

489

490

491

492

493

494

495

496

497

498

499

500

501

502

503

504

505

506

507

508

509

510

511

512

513

\section{LIST OF FIGURES}

Figure 1 - Visual aspect of the recycled C\&DW (ruler in centimetres).

Figure 2 - Particle size distribution of the Recycled C\&DW and gradation requirements of FHWA and NCMA.

Figure 3 - Comparison of shear stress-shear displacement curves achieved for recycled C\&DW and natural sands $(\sigma=50 \mathrm{kPa})$.

Figure 4 - Direct shear behaviour of recycled C\&DW under distinct normal stress values.

Figure 5 - Failure envelopes for C\&DW peak shear strength.

Figure 6 - Failure envelopes for C\&DW peak shear strength and large displacement shear strength.

Figure 7 - Results of direct shear tests for: a) C\&DW/GGR1 interface; b) C\&DW/GGR2 interface; c) C\&DW/GCR interface.

Figure 8 - Failure envelopes for peak and large displacement shear strength of: a) C\&DW/GGR1 interface; b) C\&DW/GGR2 interface; c) C\&DW/GCR interface.

Figure 9 - Coefficients of interaction for peak shear strength against normal stress.

(1)

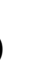


514 LIST OF TABLES

515 Table 1 - Properties of the geosynthetics.

516 Table 2 - Leaching test results.

517 Table 3 - Summary of shear strength parameters for C\&DW/geosynthetic interfaces.

518

519

520

521

522

523

524

525

526

527

528

529

530

531

532

533

534

535

536

537

538

539

540

541

542

543

544

545 


\section{FIGURES}

547

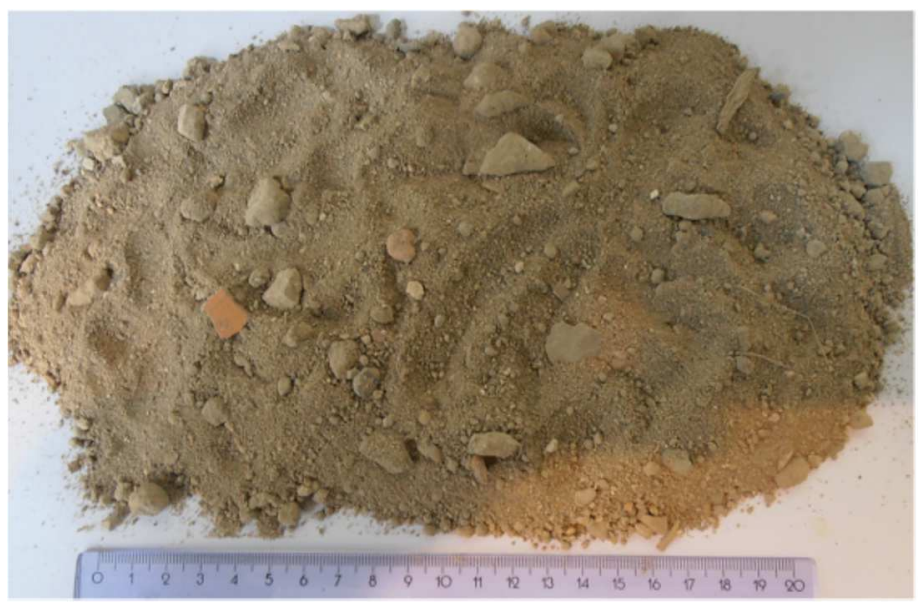

549 Figure 1 - Visual aspect of the recycled C\&DW (ruler in centimetres).

550

551

552

553

554

555

556

557

558

559

560

561

562

563

564

565 


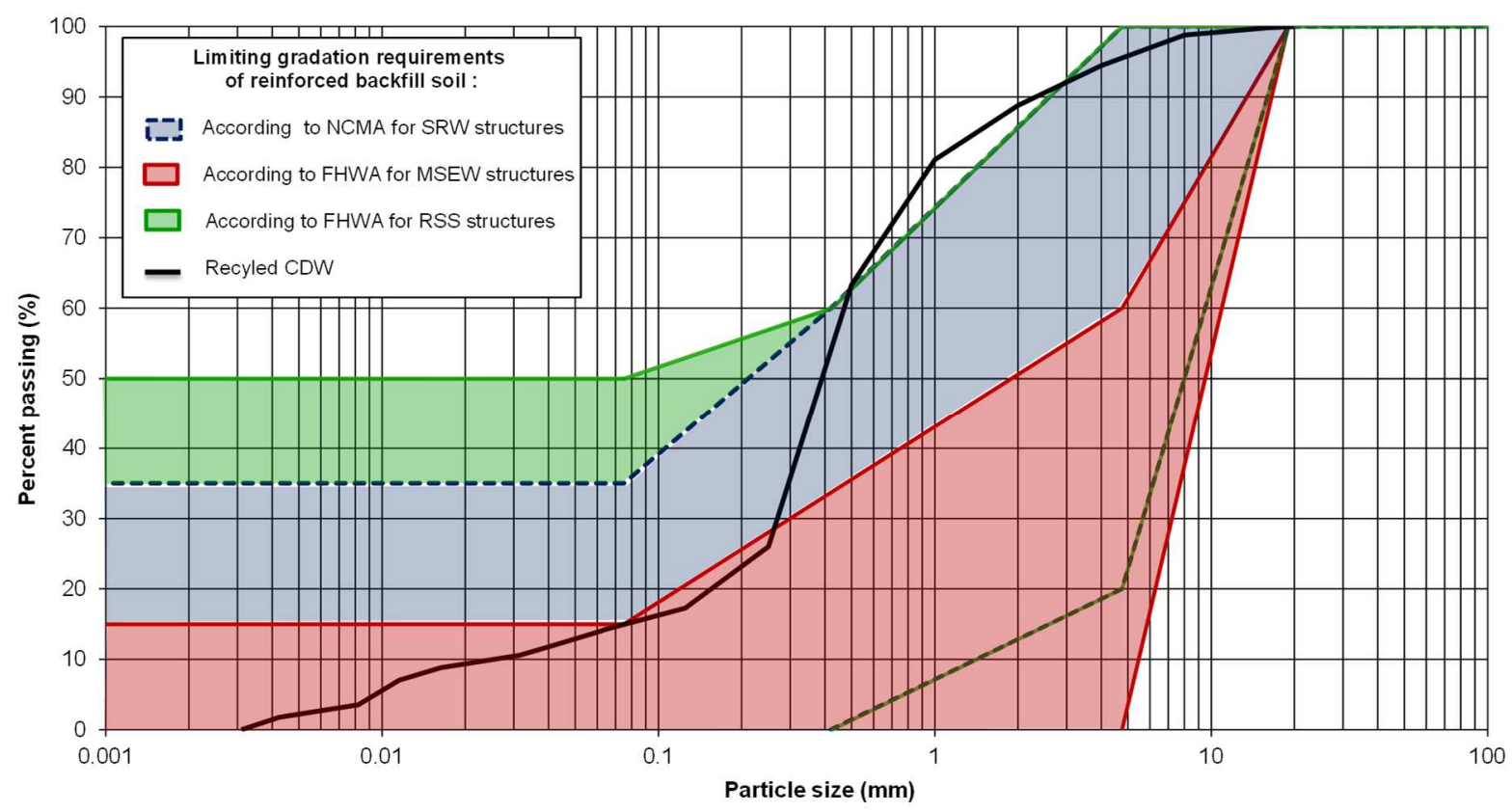

Figure 2 - Particle size distribution of the Recycled C\&DW and gradation requirements of 568 FHWA and NCMA.

569

570

571

572

573

574

575

576

577

578

579

580

581

582

583

584

585

586

587 


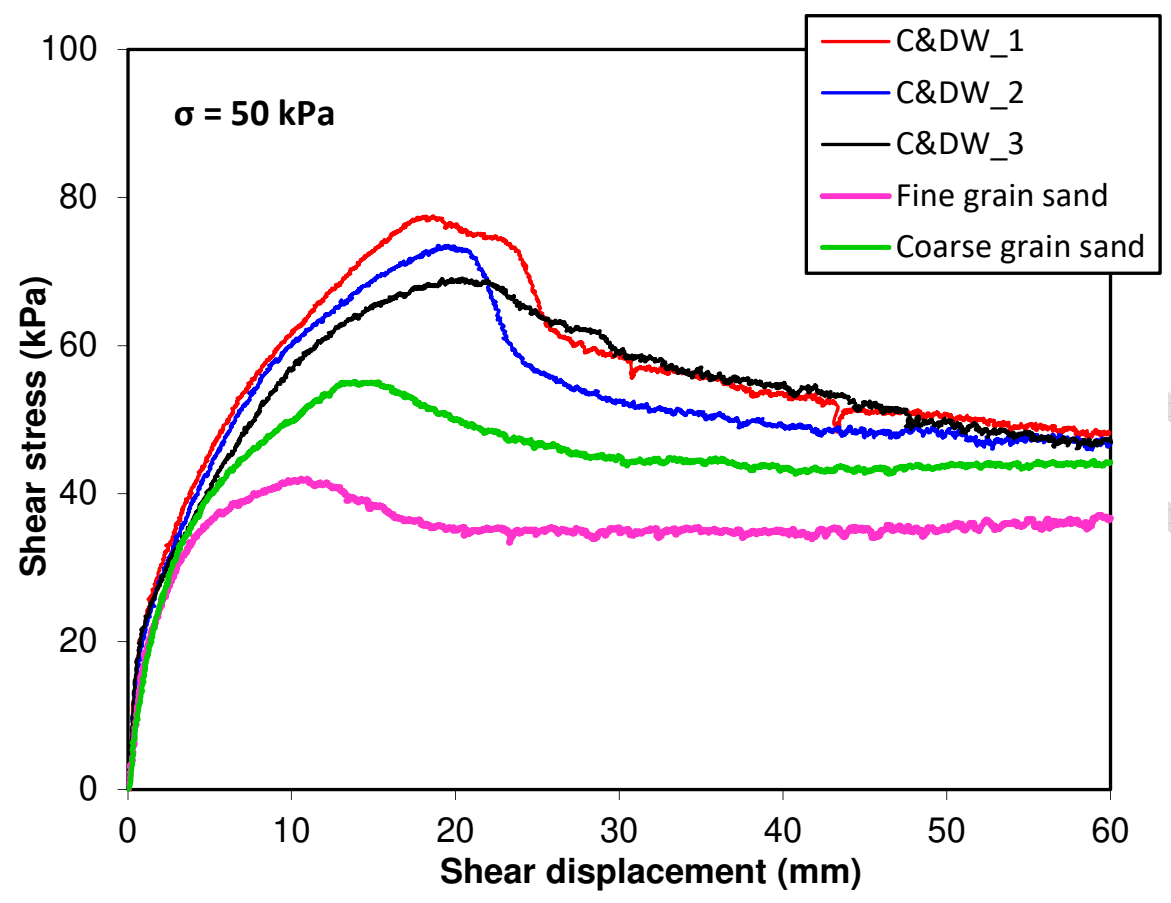

590

Figure 3 - Comparison of shear stress-shear displacement curves achieved for recycled

592 C\&DW and natural sands $(\sigma=50 \mathrm{kPa})$.

593

594

595

596

597

598

599

600

601

602

603

604

605

606

607

608 
609

610

611

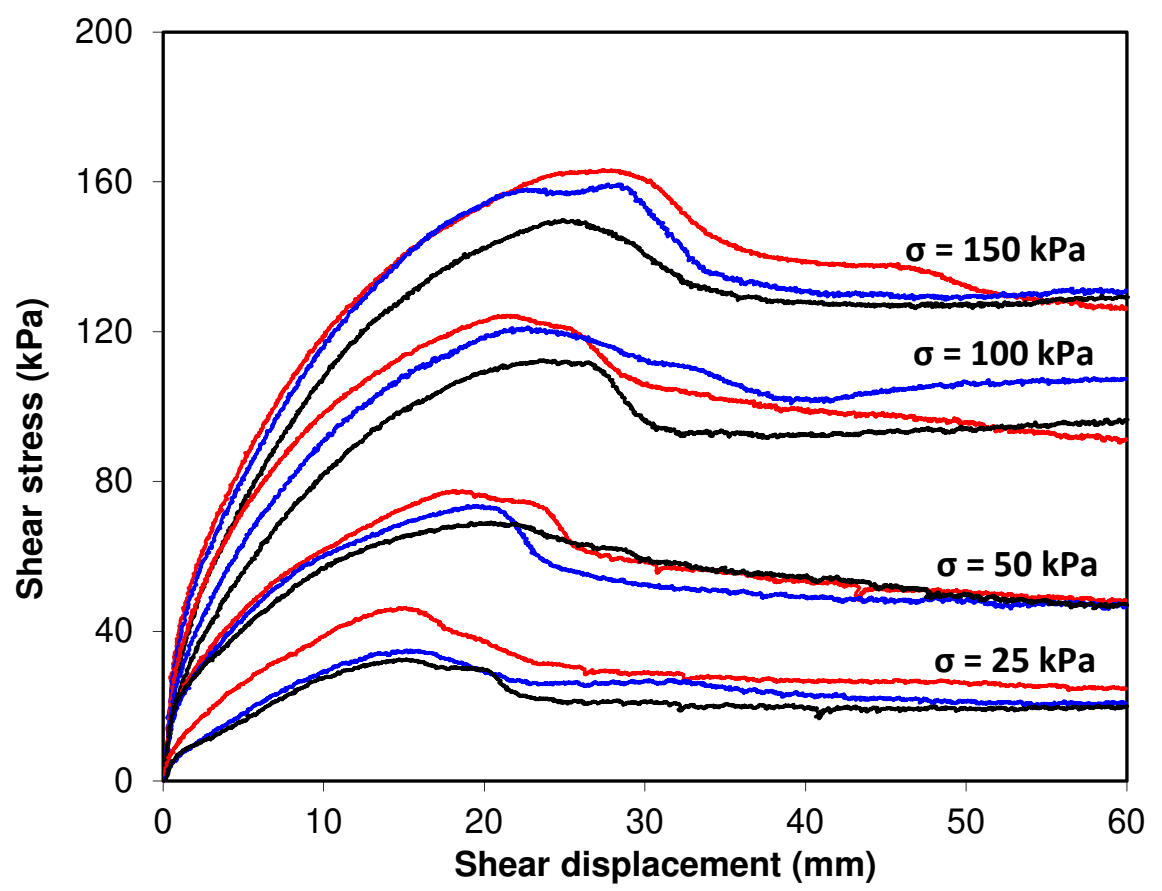

612

613 Figure 4 - Direct shear behaviour of recycled C\&DW under distinct normal stress values.

614

615

616

617

618

619

620

621

622

623

624

625

626

627

628

629 


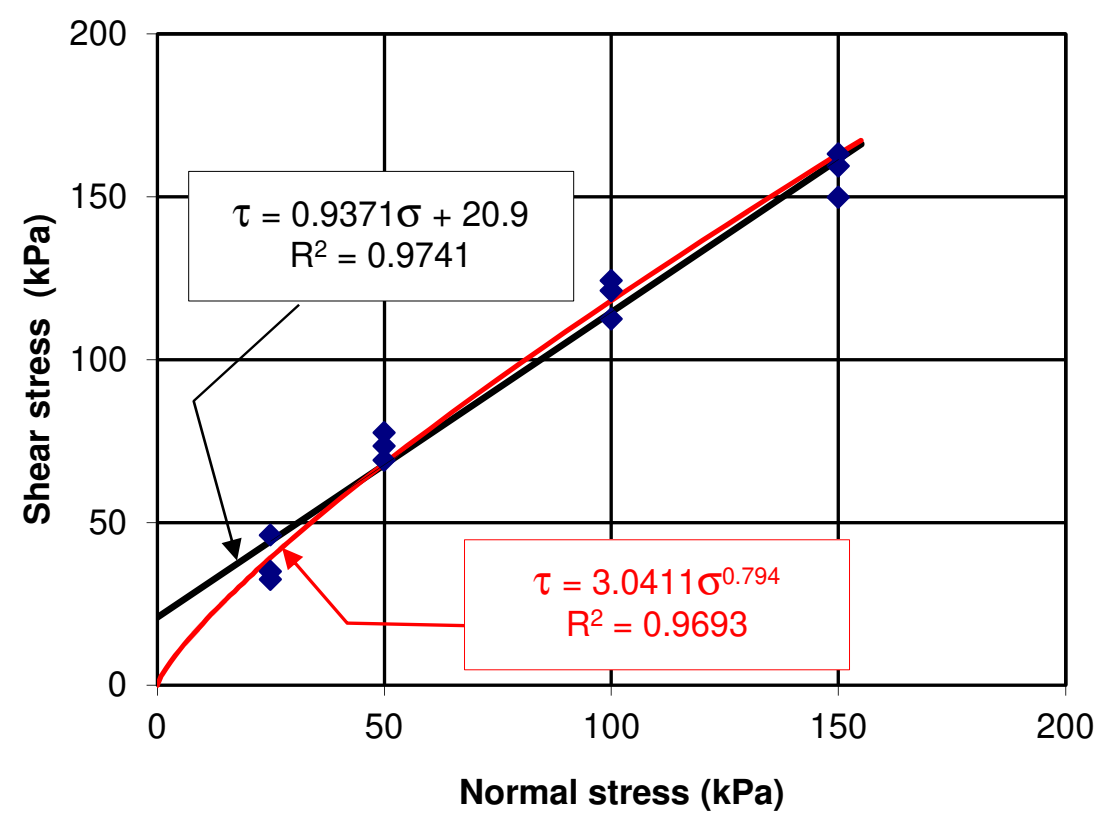

631

632 Figure 5 - Failure envelopes for C\&DW peak shear strength.

633

634

635

636

637

638

639

640

641

642

643

644

645

646

647

648

649

650

651 


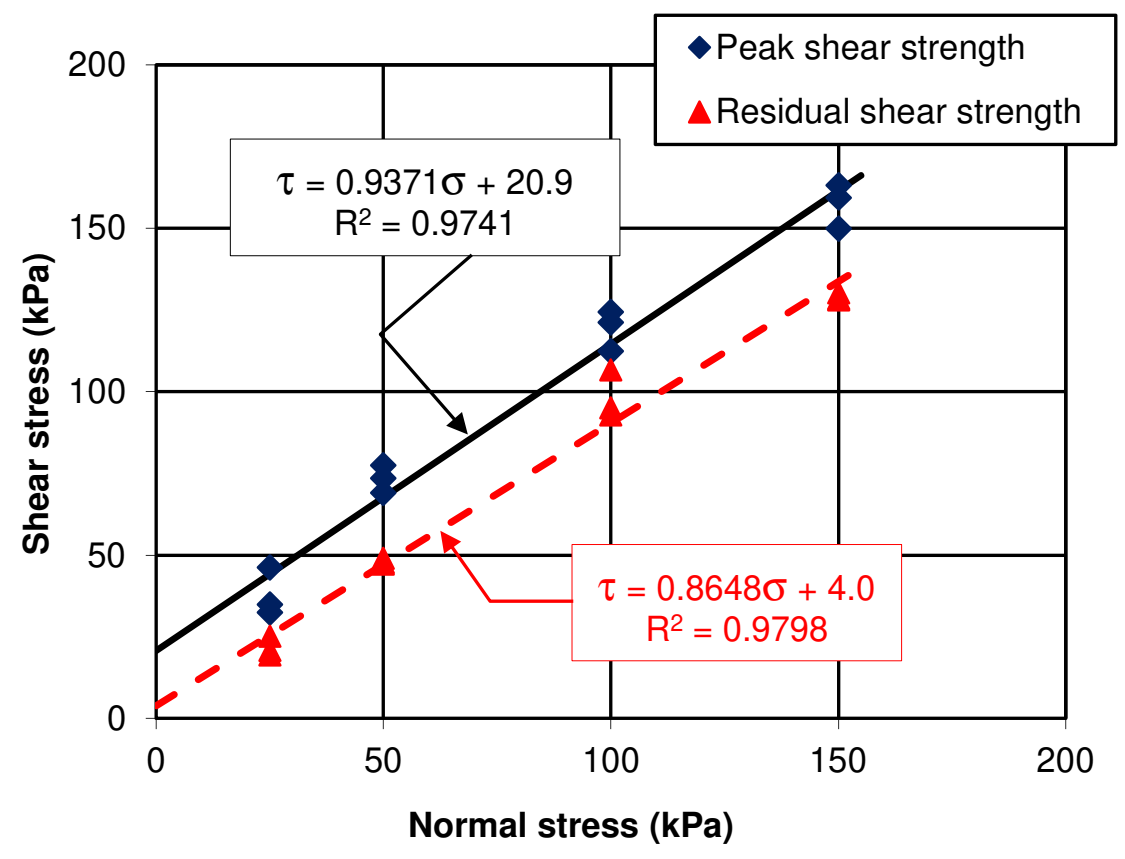

653

654 Figure 6 - Failure envelopes for C\&DW peak shear strength and large displacement shear 655 strength.

656

657

658

659

660

661

662

663

664

665

666

667

668

669

670

671

672

673 


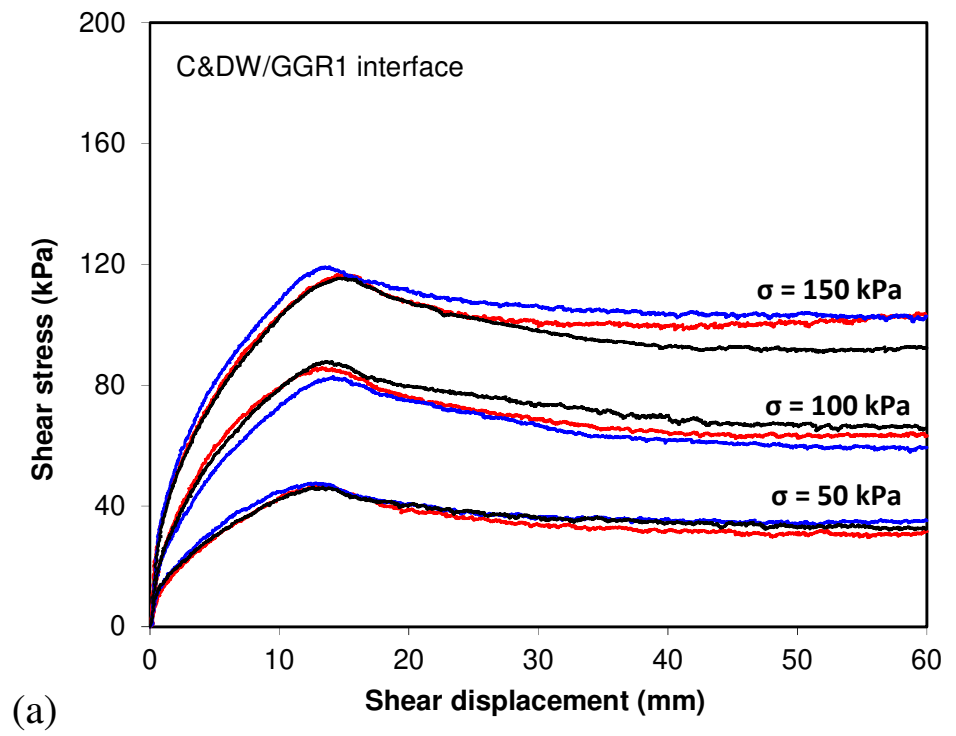

674

(a)

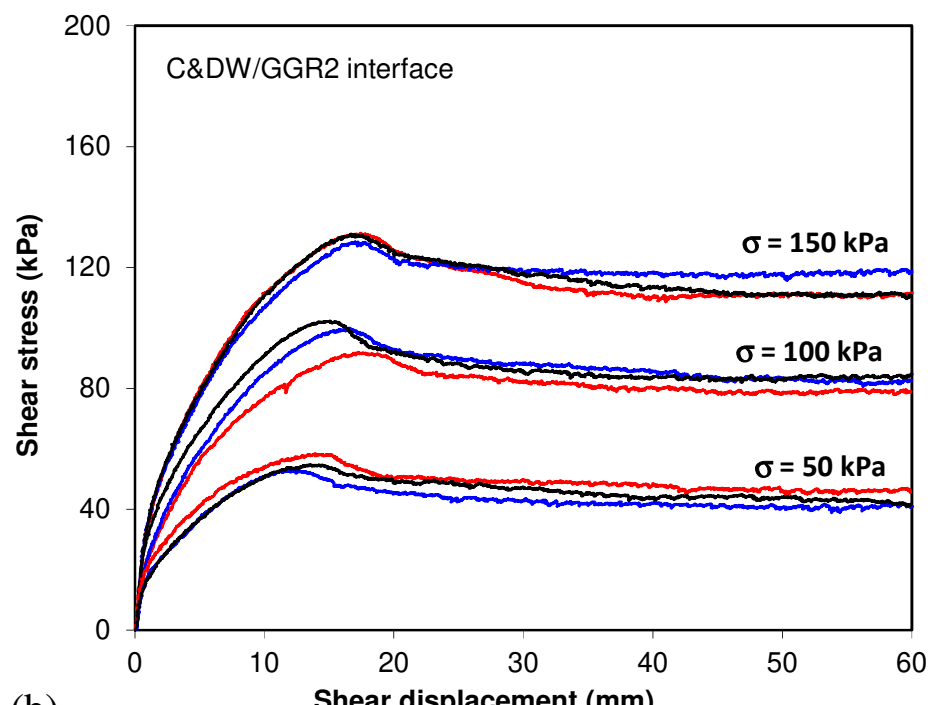

675

(b)

Shear displacement (mm)

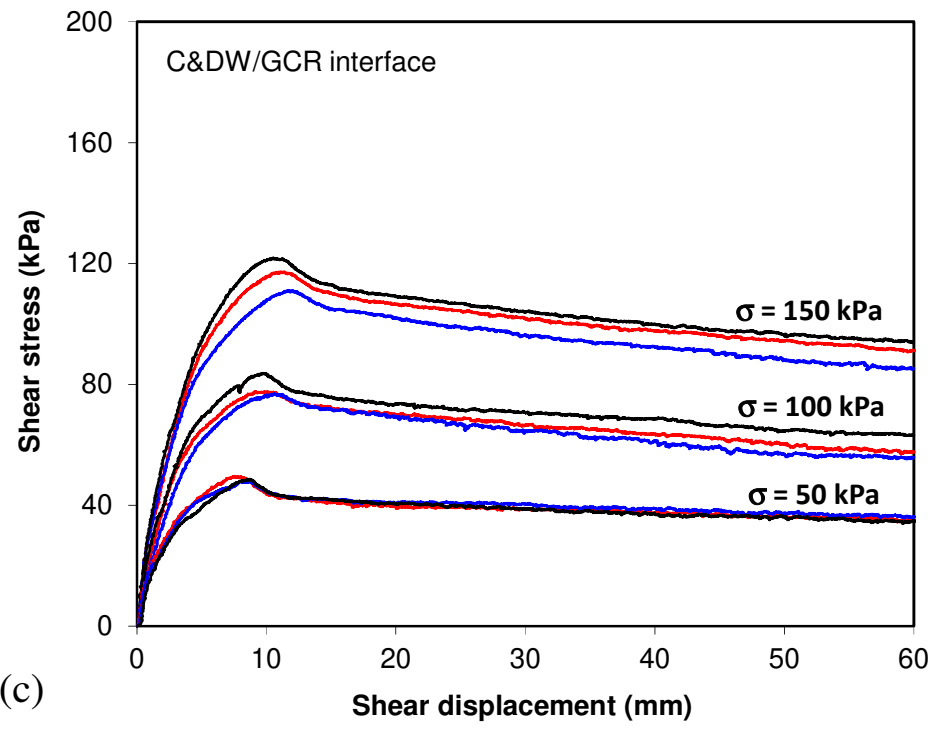


677 Figure 7 - Results of direct shear tests for: a) C\&DW/GGR1 interface; b) C\&DW/GGR2 678 interface; c) C\&DW/GCR interface.

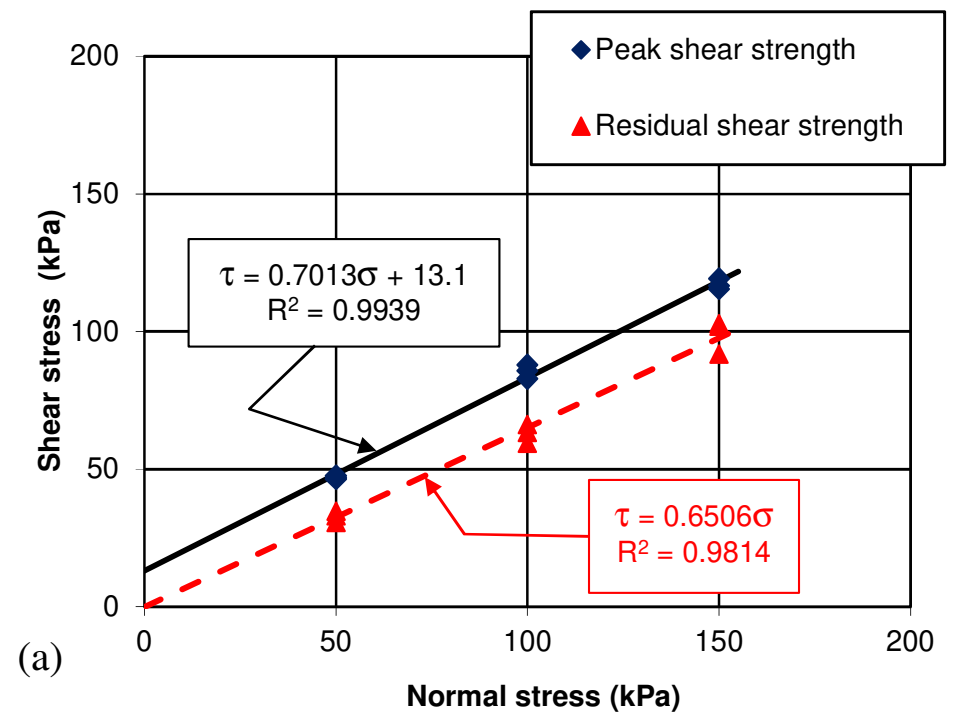

679

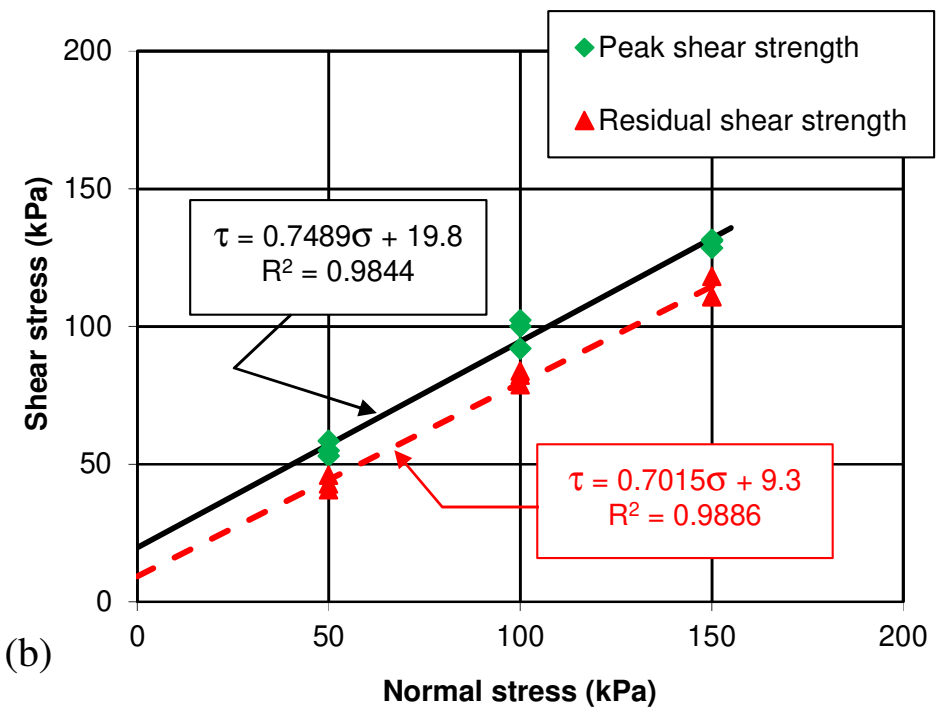

680 


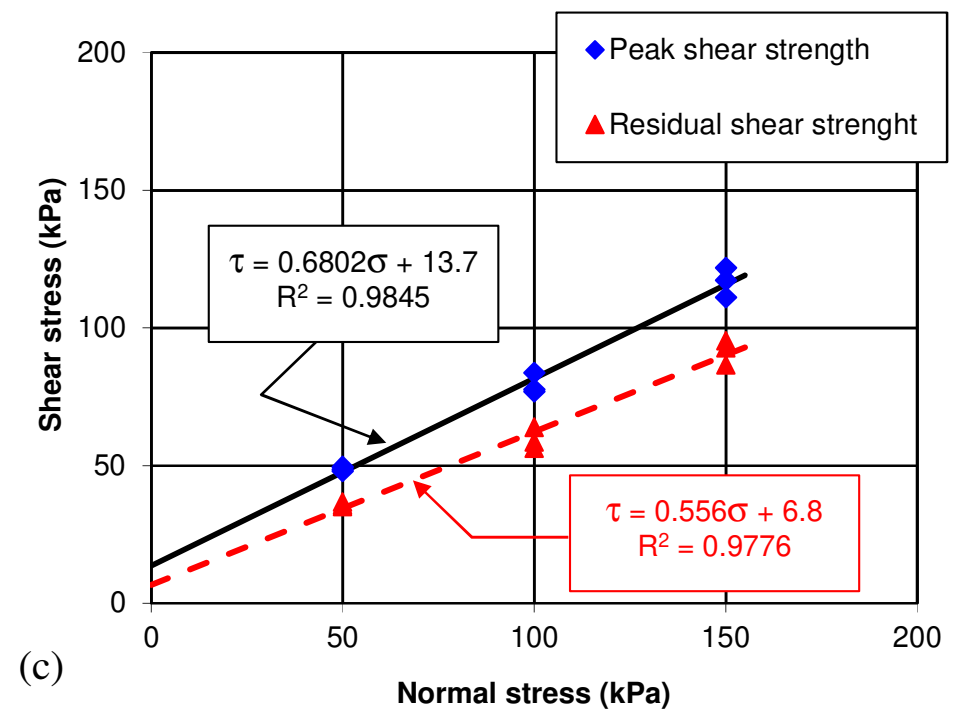

681

682 Figure 8 - Failure envelopes for peak and large displacement shear strength of:

683 a) C\&DW/GGR1 interface; b) C\&DW/GGR2 interface; c) C\&DW/GCR interface.

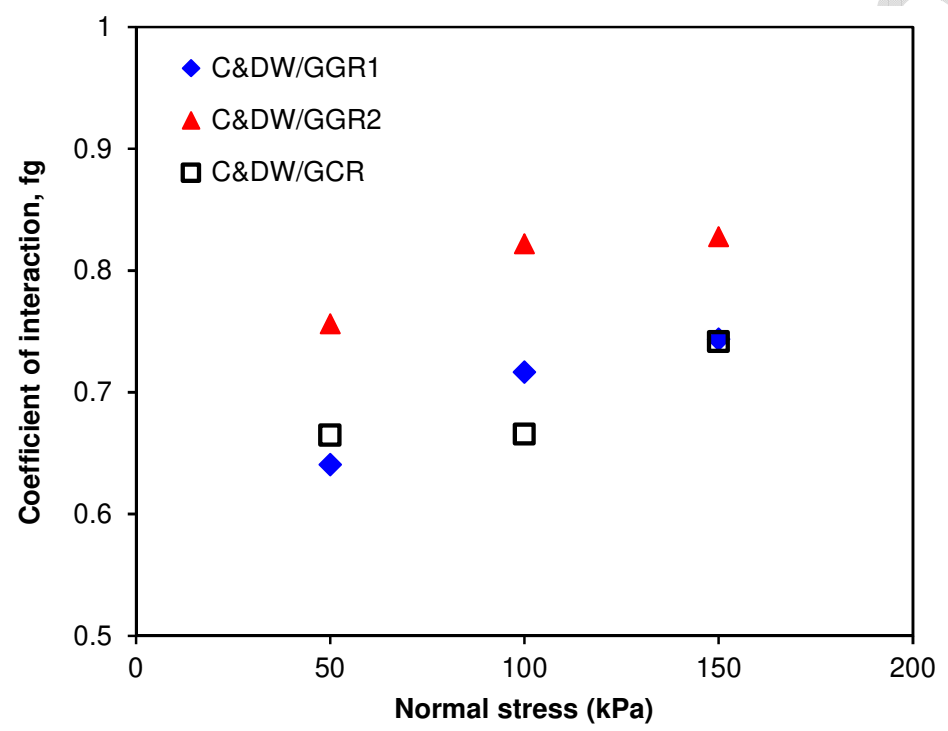

684

685 Figure 9 - Coefficients of interaction for peak shear strength against normal stress.

686

687

688

689

690

691

692

693

694 
TABLES

696 Table 1 - Properties of the geosynthetics.

\begin{tabular}{llll}
\hline & GGR1 & GGR2 & GCR \\
\hline Raw material & HDPE & PET & PP \& PET \\
Mass per unit area $\left(\mathrm{g} / \mathrm{m}^{2}\right)$ & 450 & 380 & 340 \\
Aperture dimensions $(\mathrm{mm})$ & $16 \times 219$ & $30 \times 73$ & - \\
Mean value of the tensile strength $(\mathrm{kN} / \mathrm{m})$ & 60 & 88 & 71 \\
Elongation at maximum load, $\boldsymbol{\varepsilon}_{\mathrm{T} \max }(\%)$ & 10 & 9 & 10 \\
Secant tensile stiffness at 2\% strain $(\mathrm{kN} / \mathrm{m})$ & 1085 & 1182 & 647 \\
Secant tensile stiffness at $5 \%$ strain $(\mathrm{kN} / \mathrm{m})$ & 718 & 928 & 577 \\
Secant tensile stiffness at $\boldsymbol{\varepsilon}_{\mathrm{T} \max }(\mathrm{kN} / \mathrm{m})$ & 597 & 907 & 728 \\
\hline
\end{tabular}

697

698

699

700

701

702

703

704

705

706

707

708

709

710

711

712

713

714

715

716

717

718

719 
Table 2 - Leaching test results.

\begin{tabular}{lll}
\hline Parameter & $\begin{array}{l}\text { Value } \\
(\mathrm{mg} / \mathrm{kg})\end{array}$ & $\begin{array}{l}\text { Acceptance criteria for leached } \\
\text { concentrations - Inert landfill }\end{array}$ \\
\hline Arsenic, $\mathrm{As}$ & 0.020 & 0.5 \\
Lead, $\mathrm{Pb}$ & $<0.01$ & 0.5 \\
Cadmium, Cd & $<0.003$ & 0.04 \\
Chromium, Cr & 0.015 & 0.5 \\
Copper, $\mathrm{Cu}$ & 0.12 & 2 \\
Nickel, $\mathrm{Ni}$ & $<0.01$ & 0.4 \\
Mercury, $\mathrm{Hg}$ & $<0.002$ & 0.01 \\
Zinc, $\mathrm{Zn}$ & $<0.1$ & 4 \\
Barium, Ba & 0.12 & 20 \\
Molybdenum, Mo & 0.027 & 0.5 \\
Antimony, Sb & $<0.01$ & 0.06 \\
Selenium, Se & $<0.02$ & 0.1 \\
Chloride, Cl & 130 & 800 \\
Fluoride, F & 2.7 & 10 \\
Sulphate, SO 4 & 1900 & 1000 \\
Dissolved Organic Carbon (DOC) & 47 & 500 \\
Dissolved Solids, DS (mg/kg) & 2630 & 4000 \\
\hline pH & 7.8 & - \\
\hline
\end{tabular}

722

723 
738 Table 3 - Summary of shear strength parameters for C\&DW/geosynthetic interfaces.

\begin{tabular}{l|ll|ll}
\hline & \multicolumn{2}{|l|}{ Peak shear strength } & \multicolumn{2}{l}{ Residual shear strength } \\
\hline Interface & $\delta_{\mathrm{p}}\left(^{\circ}\right)$ & $\mathrm{c}_{\mathrm{a}, \mathrm{p}}(\mathrm{kPa})$ & $\delta_{\mathrm{cv}}\left({ }^{\circ}\right)$ & $\mathrm{c}_{\mathrm{a}, \mathrm{cv}}(\mathrm{kPa})$ \\
\hline C\&DW/GGR1 & 35.0 & 13.1 & 33.0 & 0 \\
C\&DW/GGR2 & 36.8 & 19.8 & 35.0 & 9.3 \\
C\&DW/GCR & 34.2 & 13.7 & 29.1 & 6.8 \\
\hline
\end{tabular}

739

740

741

742

743

744

745

746

747

748

749

750

751

752

753

754

755

756

757

758

759

760

761

762

763

764 